\title{
Osmotic demyelination syndrome and thoughts on its prevention
}

\author{
Philip J. G. M. Voets ${ }^{1} \cdot$ Roderick P. P. W. M. Maas $^{2} \cdot$ Nils P. J. Vogtländer $^{3} \cdot$ Karin A. H. Kaasjager $^{1}$
}

Received: 24 April 2021 / Accepted: 24 May 2021 / Published online: 5 June 2021

(c) The Author(s) 2021

Keywords Hyponatremia $\cdot$ Osmotic demyelination syndrome $\cdot$ Desmopressin clamp $\cdot$ Equation

\section{Introduction}

Osmotic demyelination syndrome (ODS) is a devastating clinical repercussion of the body's inability to accurately respond to a rapid rise in plasma tonicity. It usually occurs in malnourished individuals with long-standing hyponatremia that was corrected too rapidly (Fig. 1) [1, 2]. Here, after presenting a patient who unfortunately developed ODS, we discuss novel insights into its prevention.

The case. A 46-year-old female patient with a medical history of hypertension, for which she used hydrochlorothiazide, presented to the Emergency Department with confusion and lethargy. Over the previous weeks, she had consumed excessive amounts of alcohol, accompanied by poor oral intake. Her general physical examination was unremarkable, except for a heart rate of 110 beats per minute. She was normotensive and weighed $62 \mathrm{~kg}$. Neurological examination revealed disorientation, restless behavior, and a staggering gait, but no paresis or appendicular ataxia. A CT scan excluded structural intracerebral abnormalities. Her plasma sodium concentration turned out to be $95 \mathrm{mmol} / \mathrm{L}$ with a measured plasma osmolarity of $198 \mathrm{mOsmol} / \mathrm{L}$. Her plasma potassium concentration was also low at $2.9 \mathrm{mmol} / \mathrm{L}$ and she was normoglycemic. Urine osmolarity on admission was $248 \mathrm{mOsmol} / \mathrm{L}$, implying non-osmotic antidiuretic hormone $(\mathrm{ADH})$ release in the context of profound hyponatremia, with a urine sodium concentration of $36 \mathrm{mmol} / \mathrm{L}$.

Philip J. G. M. Voets

P.J.G.Voets@umcutrecht.nl

1 Department of Nephrology, University Medical Centre Utrecht, Heidelberglaan 100, 3584 CX Utrecht, The Netherlands

2 Department of Neurology, Radboud University Medical Centre, Nijmegen, The Netherlands

3 Department of Nephrology, Gelre Hospital Apeldoorn, Apeldoorn, The Netherlands
Hypothyroidism and hypocortisolism were ruled out. The internist concluded that her hypotonic hyponatremia was probably caused by chronic hydrochlorothiazide use and poor oral intake and ordered boluses of hypertonic saline $(3.0 \%-\mathrm{NaCl})$, striving for a maximum correction rate of the plasma sodium concentration of $10 \mathrm{mmol} / \mathrm{L}$ in the first $24 \mathrm{~h}$. Her plasma sodium concentration and urine output were strictly monitored (Table 1 ). Her plasma sodium concentration increased by $5 \mathrm{mmol} / \mathrm{L}$ in the first $7 \mathrm{~h}$, which prompted conversion to a $5.0 \%$-glucose infusion. After $6 \mathrm{~h}$ of stable plasma sodium concentrations, infusion was switched to $2.5 \%$-glucose $/ 0.45 \%-\mathrm{NaCl}$. The correction was then suddenly accompanied by massive diuresis and a decrease in urine osmolarity to $46 \mathrm{mOsmol} / \mathrm{L}$. Seventeen hours after presentation, her plasma sodium concentration was $105 \mathrm{mmol} / \mathrm{L}$. As a rescue strategy, intravenous desmopressin was administered along with 5.0\%-glucose infusion. Over the following days, her plasma sodium concentration gradually increased toward normonatremia. A week later, however, she developed severe tetraparesis and respiratory insufficiency requiring orotracheal intubation. A brain MRI scan showed $\mathrm{T}_{2} /$ FLAIR-hyperintense, $\mathrm{T}_{1}$-hypointense signals centrally in the pons, basal ganglia, and thalami, confirming the diagnosis of ODS.

\section{Lessons for the clinical nephrologist}

Our case demonstrates the dramatic neurological sequelae of an overly rapid correction of profound hypotonic hyponatremia of multifactorial aetiology, which-although anticipated-could not be prevented [1-3]. Here, saline infusion removed the hydrochlorothiazide-induced hypovolemic ADH stimulus, which resulted in a considerable increase in renal free water clearance and a steep rise in plasma sodium concentration. This dangerous phenomenon is commonly referred to as "auto-correction" [4]. It should be noted 


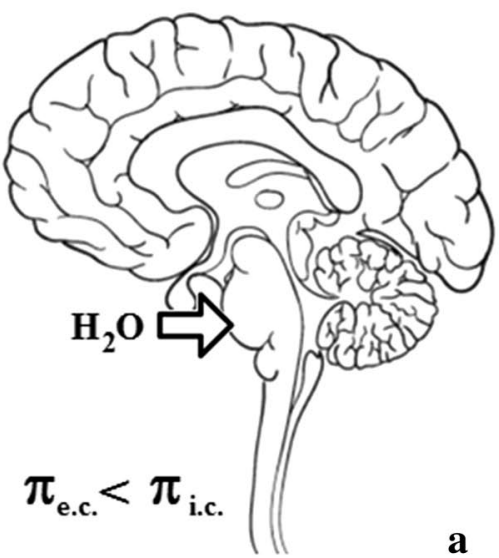

a

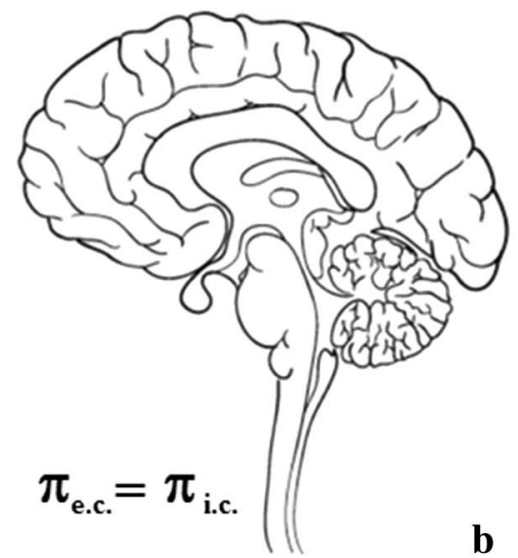

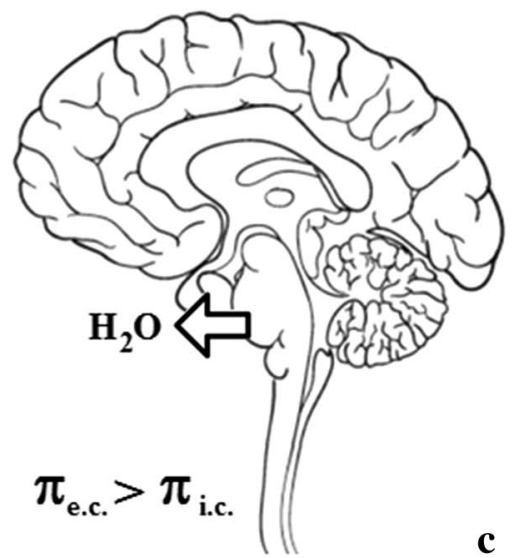

Fig. 1 Osmotic water movement in the brain and pathophysiology of osmotic demyelination syndrome. If the effective osmolarity of the extracellular compartment $\left(\pi_{\text {e.c. }}\right)$ is lower than the effective osmolarity of the intracellular compartment $\left(\pi_{\mathrm{i} . \mathrm{c}}\right)$, water moves into the brain cells (a). This occurs in hypotonic hyponatremia. If the effective osmolarity of the extracellular compartment subsequently becomes equal to the effective osmolarity of the intracellular compartment, movement of water between both compartments ceases (b). This occurs when brain cells have adjusted their intracellular osmolarity to hypotonic hyponatremia by reducing their cytosolic solute content. If the effective osmolarity of the extracellular compartment is higher than the effective osmolarity of the intracellular compartment, water moves out of the brain cells (c). This occurs if long-standing hypotonic hyponatremia is corrected. If the water losses in (c) are large enough and occur relatively rapidly $(>8 \mathrm{mmol} / \mathrm{L} /$ day), massive lysis of glial cells may ensue, leading to osmotic demyelination syndrome (ODS). The arrow in (a) points toward the basilar part of the pons, which contains fibers of the corticospinal and corticobulbar tracts and is especially vulnerable to a rapid rise in plasma osmolarity. In addition to central pontine myelinolysis, characterized by spastic tetraparesis, dysarthria, and dysphagia, there is frequently involvement of other central nervous system structures, such as the basal ganglia and thalami (extrapontine myelinolysis) [1]

Table 1 Course of the patient's plasma sodium concentration (where (A) refers to a radial artery puncture), urine osmolarity, urine output, and intervention on the day of her admission

\begin{tabular}{lllll}
\hline $\begin{array}{l}\text { Hours since } \\
\text { admission }\end{array}$ & Plasma sodium concentration & Urine osmolarity & Urine output & Intervention \\
\hline 0 & $95 \mathrm{mmol} / \mathrm{L}$ & $248 \mathrm{mOsmol} / \mathrm{L}$ & - & $3.0 \%$-NaCl (bolus of $100 \mathrm{~mL})$ \\
1 & $<100 \mathrm{mmol} / \mathrm{L}(\mathrm{A})$ & $246 \mathrm{mOsmol} / \mathrm{L}$ & $125 \mathrm{~mL} / \mathrm{h}$ & - \\
2 & $98 \mathrm{mmol} / \mathrm{L}$ & - & $100 \mathrm{~mL} / \mathrm{h}$ & Ringer's infusate (bolus of $250 \mathrm{~mL})$ \\
3 & $98 \mathrm{mmol} / \mathrm{L}$ & - & $100 \mathrm{~mL} / \mathrm{h}$ & - \\
5 & $100 \mathrm{mmol} / \mathrm{L}(\mathrm{A})$ & $102 \mathrm{mOsmol} / \mathrm{L}$ & $200 \mathrm{~mL} / \mathrm{h}$ & $5.0 \%$-glucose $(\mathrm{bolus}$ of $1000 \mathrm{~mL})$ \\
10 & $102 \mathrm{mmol} / \mathrm{L}$ & $173 \mathrm{mOsmol} / \mathrm{L}$ & - & $2.5 \%$-glucose $/ 0.45 \%$ - $\mathrm{NaCl}(? \mathrm{~mL})$ \\
12 & $101 \mathrm{mmol} / \mathrm{L}$ & $252 \mathrm{mOsmol} / \mathrm{L}$ & $400 \mathrm{~mL} / \mathrm{h}$ & $2.5 \%$-glucose $/ 0.45 \%-\mathrm{NaCl}(? \mathrm{~mL})$ \\
15 & $102 \mathrm{mmol} / \mathrm{L}$ & $152 \mathrm{mOsmol} / \mathrm{L}$ & $700 \mathrm{~mL} / \mathrm{h}$ & $5.0 \%$-glucose $(1000 \mathrm{~mL} / \mathrm{h})$ \\
17 & $105 \mathrm{mmol} / \mathrm{L}$ & $46 \mathrm{mOsmol} / \mathrm{L}$ & $850 \mathrm{~mL} / \mathrm{h}$ & $5.0 \%$-glucose $(? \mathrm{~mL}) / \mathrm{DDAVP}$ \\
18 & $102 \mathrm{mmol} / \mathrm{L}$ & $92 \mathrm{mOsmol} / \mathrm{L}$ & $1150 \mathrm{~mL} / \mathrm{h}$ & $5.0 \%$-glucose $(? \mathrm{~mL}) / \mathrm{DDAVP}$ \\
22 & $100 \mathrm{mmol} / \mathrm{L}$ & $50 \mathrm{mOsmol} / \mathrm{L}$ & $700 \mathrm{~mL} / \mathrm{h}$ & $5.0 \%$-glucose $(? \mathrm{~mL}) / \mathrm{DDAVP}$ \\
\hline
\end{tabular}

It can be seen that an increase in the plasma sodium concentration of $10 \mathrm{mmol} / \mathrm{L}$ occurred in the first $17 \mathrm{~h}$ after admission, exceeding the maximum allowable correction rate

that the mechanism of thiazide-associated hyponatremia is probably more complex than simple hypovolemia-mediated $\mathrm{ADH}$ release and has recently been shown to also involve disrupted prostaglandin $\mathrm{E}_{2}$ transport in the renal tubular epithelium [5]. Furthermore, reintroduction of solutes in the form of saline after a prolonged period of inadequate intake strongly increased the patient's urine output, adding to the auto-correction [4]. Her poor intake may also have contributed to intravascular volume depletion. The depth of the patient's plasma sodium concentration and her responsiveness on presentation imply that the hypotonic hyponatremia was chronic in nature. Therefore, her pontine cells will have had ample time to adapt to the chronic plasma hypotonicity by decreasing their cytoplasmic solute content, but not enough time to adjust to the rapid rise in plasma sodium concentration when the hypovolemic ADH stimulus was removed. It could be argued that her "malnourished" pontine cells were already less capable of adjusting their intracellular 
solute content in response to any increase in extracellular tonicity [1]. Hypokalemia has also been described as a risk factor for the development of ODS, probably because it often reflects a poor nutritional status or hypovolemic activation of the renin-angiotensin-aldosterone system, both of which predispose for auto-correction [1]. In our case, however, the observed hypokalemia was most likely the result of chronic hydrochlorothiazide use and malnutrition.

\section{Proactive desmopressin clamp, the Voets equation and hypertonic saline}

In order to forestall neurological complications, guidelines recommend a maximum allowable correction rate of the plasma sodium concentration of 8 to $10 \mathrm{mmol} / \mathrm{L}$ in the first $24 \mathrm{~h}$, followed by $8 \mathrm{mmol} / \mathrm{L}$ per $24 \mathrm{~h}$ over the next days [2, $3]$. The maximum allowable correction of extreme hyponatremia should be even slower, since the relative increase in plasma tonicity is larger. A proactive "desmopressin clamp" (PDC) with hypertonic saline boluses is an effective, safe, but relatively unfamiliar treatment strategy for patients with severe hypotonic hyponatremia who are at risk for rapid auto-correction and ODS [6, 7]. PDC, although counterintuitive at first glance, is intended to control renal free water clearance through the administration of desmopressin, a synthetic $\mathrm{ADH}$ analogue. A rational initial dose is $2 \mu \mathrm{g}$ i.v., after which the following doses depend on urine osmolarity and output $[6,7]$. The treating physician can then correct the plasma sodium concentration in a controlled fashion by administering calculated hypertonic saline boluses without being surprised by sudden water diuresis when the endogenous ADH release falls $[6,7]$. This proactive strategy is different from a reactive strategy or rescue strategy, as was attempted in the discussed patient [7].

The central problem for physicians when initiating a PDC is to accurately predict the increase in plasma sodium concentration in response to saline infusate to make sure that the correction limit is not exceeded. Many physicians rely on the Adrogue-Madias equation to estimate this change [4, 6, 8]. A major and frequently cited issue with this model is that it solely looks at the redistribution of crystalloid infusate and disregards any subsequent renal water and solute handling. Therefore, calculations according to the Adrogue-Madias equation are short-term predictions, and their accuracy quickly breaks down as time passes [8, 9]. Ignoring renal infusate handling will lead to an imprecise prediction of the "net"-clinically relevant-effect of saline infusion on the plasma sodium concentration. A novel model-hereafter referred to as the Voets equation-has recently been derived and validated for syndrome of inappropriate antidiuretic hormone (SIADH) patients. This model is based on the electrolyte-free water balance that considers both infusate input and renal output under the condition of relatively fixed urine osmolarity. Therefore, it is an ideally suited model to predict the net change in plasma sodium concentration in response to crystalloid infusate boluses with a PDC (dubbed "therapeutic SIADH") [8, 9]. Because sudden changes in endogenous $\mathrm{ADH}$ release are not an issue with a PDC, the patient essentially has a fixed urine osmolarity. For this particular scenario, we believe that the Voets equation-Eq. (1) below-is conceptually better suited than the Adrogue-Madias model, as previously shown for SIADH patients: [8, 9]

$\Delta\left[N a^{+}\right]_{p}=\frac{\left[N a^{+}\right]_{p} V_{i}}{T B W}\left(1.7 \frac{o_{i}}{o_{u}}-1\right)$

Here, the parameters $\Delta\left[\mathrm{Na}^{+}\right]_{p},\left[\mathrm{Na}^{+}\right]_{p}, V_{i}, T B W, O_{i}$, and $O_{u}$ represent the predicted change in plasma sodium concentration, initial plasma sodium concentration, infusate volume, total body water, infusate osmolarity (which equals infusate tonicity for crystalloid fluids), and urine osmolarity, respectively [8]. Suppose that a PDC is applied to the previously presented patient with total body water of $31 \mathrm{~L}$, as estimated from her body weight, and that her urine osmolarity is clamped at approximately $250 \mathrm{mOsmol} / \mathrm{L}$, which corresponds to her urine osmolarity on admission. This is desirable as PDC merely sets the stage for a controlled correction of the plasma sodium concentration; it should not in itself induce significant changes in free water clearance. According to the Voets equation, her predicted change in plasma sodium concentration in response to a $0.50 \mathrm{~L}$ $3.0 \%-\mathrm{NaCl}$ bolus (osmolarity: 1,026 $\mathrm{mOsmol} / \mathrm{L}$ ) would be $9.1 \mathrm{mmol} / \mathrm{L}:[8]$

$\Delta\left[\mathrm{Na}^{+}\right]_{p}=\frac{95 \cdot 0.5}{31}\left(1.7 \frac{1026}{250}-1\right) \approx 9.1$

By contrast, the modified Adrogue-Madias equation estimates the net effect of a $0.50 \mathrm{~L} 3.0 \%-\mathrm{NaCl}$ bolus (sodium concentration: $513 \mathrm{mmol} / \mathrm{L}$ ) on the plasma sodium concentration as follows: [4, 9]

$\Delta\left[N a^{+}\right]_{p}=\frac{V_{i}\left(\left[N a^{+}\right]_{i}-\left[N a^{+}\right]_{p}\right)}{T B W+V_{i}}=\frac{0.5(513-95)}{31+0.5} \approx 6.6$

Although no prediction model is infallible and a margin of error is inevitable, this relative underestimation of $2.5 \mathrm{mmol} / \mathrm{L}$ could encourage physicians to administer larger volumes of saline to the patient than the Voets equation suggests, potentially causing an overly rapid correction of the plasma sodium concentration. In a similar vein, a $3.0 \%-\mathrm{NaCl}$ bolus of $0.75 \mathrm{~L}$, required to increase this patient's plasma sodium concentration with $10 \mathrm{mmol} / \mathrm{L}$ according to the 
Adrogue-Madias equation, leads to an estimated change of almost $14 \mathrm{mmol} / \mathrm{L}$ when the Voets equation is applied.

In our opinion, a PDC with hypertonic saline boluses, calculated according to the Voets equation, is a rational, safe, and effective treatment strategy for hyponatremic patients at risk for auto-correction and ODS. Obviously, frequent measurements of the plasma sodium concentration remain imperative.

\section{Declarations}

Conflict of interest On behalf of all authors, the corresponding author states that there is no conflict of interest.

Ethical approval Not applicable.

Open Access This article is licensed under a Creative Commons Attribution 4.0 International License, which permits use, sharing, adaptation, distribution and reproduction in any medium or format, as long as you give appropriate credit to the original author(s) and the source, provide a link to the Creative Commons licence, and indicate if changes were made. The images or other third party material in this article are included in the article's Creative Commons licence, unless indicated otherwise in a credit line to the material. If material is not included in the article's Creative Commons licence and your intended use is not permitted by statutory regulation or exceeds the permitted use, you will need to obtain permission directly from the copyright holder. To view a copy of this licence, visit http://creativecommons.org/licenses/by/4.0/.

\section{References}

1. Abbott R, Silber E, Felber J, Ekpo E (2005) Osmotic demyelination syndrome. BMJ 331:829-830
2. Spasovski G, Vanholder R, Allolio B, Annane D, Ball S, Bichet D, Decaux G, Fenske W, Hoorn EJ, Ichai C, Joannidis M, Soupart A, Zietse R, Haller M, Van der Veer S, Van Biesen W, Nagler E (2014) Clinical practice guideline on diagnosis and treatment of hyponatraemia. Nephrol Dial Transplant 29:1-39

3. Hoorn EJ, Zietse R (2017) Diagnosis and treatment of hyponatremia: compilation of the guidelines. J Am Soc Nephrol 28:1340-1349

4. Adrogue H, Madias N (2012) The challenge of hyponatremia. J Am Soc Nephrol 23:1140-1148

5. Palmer BF, Clegg DJ (2018) Altered prostaglandin signaling as a cause of thiazide-induced hyponatremia. Am J Kidney Dis 71:769-771

6. Sterns RH, Hix JK, Silver SM (2010) Treating profound hyponatremia: a strategy for controlled correction. Am J Kidney Dis 56:774-779

7. MacMillan TE, Tang T, Cavalcanti RB (2015) Desmopressin to prevent rapid sodium correction in severe hyponatremia: a systematic review. Am J Med 128:15-24

8. Voets PJ, Vogtländer NP (2019) A quantitative approach to intravenous fluid therapy in the syndrome of inappropriate antidiuretic hormone secretion. Clin Exp Nephrol 23:1039-1044

9. Voets PJ, Vogtländer NP, Kaasjager HA (2021) Comparing the Voets equation and the Adrogue-Madias equation for predicting the plasma sodium response to intravenous fluid therapy in SIADH patients. PLoS ONE 16:e0245499

Publisher's Note Springer Nature remains neutral with regard to jurisdictional claims in published maps and institutional affiliations. 